\title{
Incidence and prevalence of Type 1 (insulin-dependent) diabetes in Estonia in 1988
}

\author{
I. Kalits ${ }^{1}$ and T. Podar ${ }^{2}$ \\ ${ }^{1}$ Republic Endocrinology Centre of the Estonian SSR, and ${ }^{2}$ Department of Medicine, Tartu University, Tartu, Estonia
}

\begin{abstract}
Summary. The objective of this study was to determine the incidence and prevalence of Type 1 (insulin-dependent) diabetes in Estonia in different sex and age groups. The data collection was based on a centralized retrospective registration of all cases of Type 1 diabetes nationwide using the records of all hospitals and polyclinics where diabetic patients are treated. In 1988, 35 new cases of Type 1 diabetes were diagnosed among children aged $0-\mathbf{1 4}$ years $(10.3$ per 100,000$)$ and 131 among the population over 15 years. The highest incidence of Type 1 diabetes $(39.9$ per 100,000$)$ was found in the age group 15-19 years. The total number of patients with
\end{abstract}

Type 1 diabetes in Estonia was 2,719 in 1988. The overall prevalence was 1.72 per 1,000 . It was highest in the age group 40-49 years (3.04 in males and 2.77 in females). In children under 15 years 204 cases of Type 1 diabetes were identified at the end of 1988. These data suggest that the risk of Type 1 diabetes in Estonia is not low, but is certainly not as high as in Finland where the population is ethnically and linguistically similar and where the highest incidence of Type 1 diabetes is found.

Key words: Incidence, prevalence, Type 1 diabetes.
A large amount of epidemiological data has been collected and marked differences in the incidence and prevalence of Type 1 diabetes worldwide have been reported [1]. Data on the incidence and prevalence of Type 1 diabetes are still missing for many populations in the world. Analyses of data from different countries will enable further insight into the aetiology of Type 1 diabetes and a strategy for the prevention of the disease might be found [2].

It has been demonstrated that Finland has the highest incidence of Type 1 diabetes in the world followed by Sweden [3]. These countries lie on the northern and eastern side of the Baltic Sea. Comparative data from the southern and eastern side of the Baltic Sea have been missing so far. In the Estonian Soviet Socialist Republic, which is situated on the eastern side of the Baltic Sea, data on the overall occurrence and prevalence of Type 1 diabetes among children and adults have been collected for some years. In 1988 a population-based investigation was initiated to study the epidemiology of Type 1 diabetes in Estonia in different sex and age groups and the results of this study are presented in this paper.

\section{Subjects and methods}

Estonia lies to the east of the Baltic Sea on the southern coast of the Gulf of Finland. The area of Estonia is about 45,000 square kilometres and the population was $1,580,430$ in 1988 . Using a rough esti- mate $60 \%$ of the population are Estonians and $40 \%$ are non-Estonians, mostly Russians. The capital of Estonia is Tallinn. Estonia has been ruled by foreigners (including Danes, Swedes, Germans and Russians) for over 700 years. Since 1940 Estonia has been one of the 15 constituent republics of the Soviet Union.

In the Soviet Union specialized endocrinological services were organized during the 1950's. The Endocrinology Centre for Soviet Estonia is located in Tartu. There is a network of endocrinologists working at the district polyclinics serving the entire country.

In Estonia, all diabetic cases must be referred to the outpatient polyclinics according to regulations of the Ministry of Health. All regional hospitals must report each new diabetic case at the time of discharge to the polyclinics or the Endocrinology Centre for the follow-up of the patients. As a rule, each patient has a specially designed card at the polyclinic containing the basic data about the disease, about specialists' consultations, and all clinical data. From these cards all information about the treated patients can be easily obtained. The doctor in charge of the follow-up is an endocrinologist, internist or paediatrician who specializes in diabetes. Insulin is free of charge for all patients. The specialist who is responsible for the follow-up of the diabetic patients has often been responsible for the newly diagnosed Type 1 diabetic patients at the regional hospital.

The diagnosis of Type 1 diabetes is made according to nationally agreed criteria for the different types of diabetes as recommended by WHO [4]. The criteria for Type 1 diabetes in children are those generally agreed for all diabetes registries [1]. The criteria for the diagnosis of Type 1 diabetes among the adult population are similar to those used by Christau and Mölbak [5]: weight loss at the time of diagnosis, manifest clinical features of the disease and/or ketonuria, fasting blood sugar values over $12 \mathrm{mmol} / \mathrm{l}$, symptoms of less than six months duration and the need for everyday insulin substitution from the diagnosis onwards. Patients 
Table 1. The incidence of Type 1 (insulin-dependent) diabetes in Estonia by age and sex in 1988

\begin{tabular}{|c|c|c|c|c|c|c|c|c|}
\hline & \multicolumn{8}{|c|}{ Age group (years) } \\
\hline & $0-4$ & $5-9$ & $10-14$ & $15-19$ & $20-29$ & $30-39$ & $40-49$ & $>50$ \\
\hline \multicolumn{9}{|l|}{ Males } \\
\hline Incidence & 1.7 & 6.9 & 12.4 & 35.6 & 10.8 & 8.2 & 9.4 & 3.2 \\
\hline $\begin{array}{l}95 \% \text { confidence } \\
\text { interval }\end{array}$ & $0.0-9.5$ & $1.9-17.7$ & $5.0-25.5$ & $20.8-27.0$ & $5.6-18.9$ & $3.8-15.6$ & $4.1-18.5$ & $1.0-7.5$ \\
\hline Number of cases & 1 & 11 & 11 & 20 & 8 & 15 & 14 & 9 \\
\hline Incidence & 1.7 & 20.2 & 20.3 & 44.3 & 7.6 & 13.9 & 15.0 & 3.5 \\
\hline $95 \%$ confidence interval & $0.0-9.5$ & $10.1-36.1$ & $10.1-36.3$ & $27.1-68.2$ & $3.3-15.0$ & $7.8-23.0$ & $8.2-25.2$ & $1.6-6.7$ \\
\hline \multicolumn{9}{|l|}{ Both sexes ${ }^{\mathrm{a}}$} \\
\hline
\end{tabular}

${ }^{a}$ In 14 cases over the age of 15 years the age group and sex could not be defined

Table 2. The prevalence of Type 1 (insulin-dependent) diabetes per 1000 in Estonia by age and sex in 1988

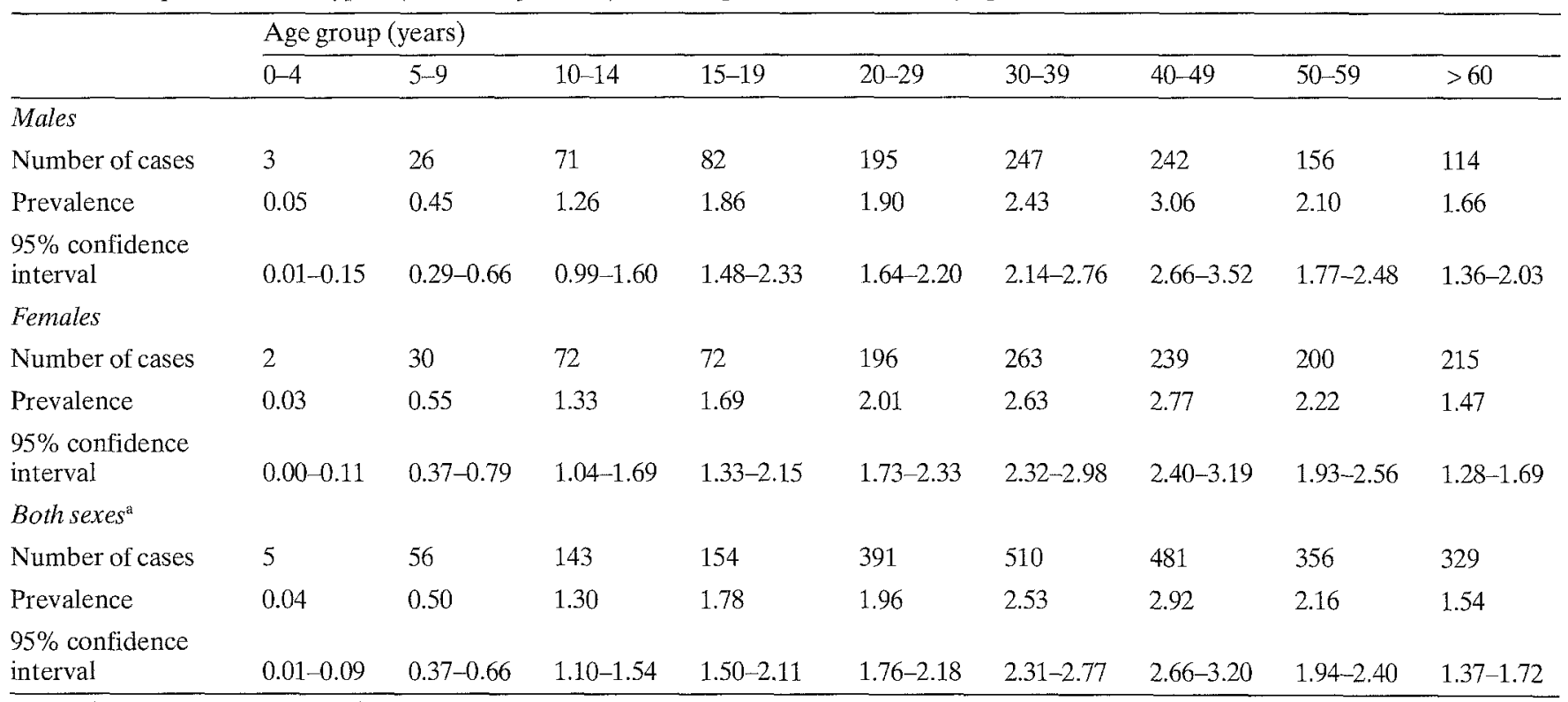

a In 294 cases over the age of 15 years the age group and sex could not be defined

who need insulin only after three or more months of oral drug treatment, are not regarded as Type 1 diabetic patients in this analysis.

At the end of each year, all doctors responsible for the follow-up of the diabetic patients report data on the patients currently treated by him/her to the Endocrinology Centre. In our study all cases of child hood Type 1 diabetes were compiled from the hospital records, or from the ambulatory cards of the polyclinics by the regional paediatricians during 1988. All cases of adult diabetes were reported by the doctors from the follow-up clinics. Data were collected at five year intervals up to the age of 20 , then onwards at 10 year intervals.

The incidence and prevalence data were obtained for all children in the different age and sex groups. The incidence data were checked and then confirmed or corrected by the regional paediatricians. All necessary information about age and sex was available for all newly diagnosed and prevalent cases of Type 1 diabetes among children under age 15 . However, in 14 of the 131 newly diagnosed adult onset cases and in 294 prevalent cases of adult Type 1 diabetes the information on age and sex was insufficient.

\section{Statistical analysis}

For the incidence and prevalence of Type 1 diabetes $95 \%$ confidence limits were estimated assuming a Poisson distribution.

\section{Results}

The incidence of Type 1 diabetes in Estonia by age and sex in 1988 is presented in Table 1. These data show that the incidence increases steeply with increasing age, ear- 
lier in girls than in boys. The highest incidence in both sexes was found in the age group 15-19 years; 35.6 for males and 44.3 for females. In the age group $20-49$ years it was 10 per 100,000 per year. Taking both sexes together the incidence of Type 1 diabetes in the age group 15-19 years was significantly higher than in any other age group. The incidence among children aged 0-14 years was 10.3 per 100,000 , and that for the age group 0-19 years was 16.7 per 100,000 . In adults over 50 years the incidence fell both in males and females. There was a slight female excess in the incidence of Type 1 diabetes in children aged $0-14$ years.

Table 2 shows the prevalence of Type 1 diabetes per 1000 in Estonia by age and sex in 1988. The overall prevalence of Type 1 diabetes in Estonia was 1.72 per 1000. In the age group 0-14 years it was about 0.60 cases per 1000 and it reached a peak in the age group $40-49$ years, 3.06 per 1000 in males and 2.77 per 1,000 in females. The prevalence of Type 1 diabetes did not differ significantly between females and males in any age group.

\section{Discussion}

Incidence data on Type 1 diabetes from Estonia are very interesting as the country lies on the Baltic Sea, an area where a marked gradient of Type 1 diabetes risk has been documented [3]. Finland and Sweden have a high incidence of childhood Type 1 diabetes, (Finland: 30.4 per 100,000 per year during 1970 to 1986; Sweden 23.8 per 100,000 per year during 1978 1986), whereas in Poland the Type 1 diabetes risk is much lower, about 4-5 per 100,000 per year during 1970-1985 [3].

The incidence of Type 1 diabetes in Estonia among children increases with age, but the peak in Type 1 diabetes incidence is not reached in childhood or puberty, but in the age group 15-19 years, contrary to many other countries. The mean age of onset of puberty in Estonia is 10 years for girls and 12 years for boys [6]. A comparison with children from Denver, Co (USA), Berlin (West Germany), Dortmund (West Germany), Stockholm (Sweden) and Melsinki (Finland) has shown that in some aspects Estonian children tend to develop faster than children from those cities [6]. In the three 5 -year age groups below 15 years the incidence of Type 1 diabetes in Estonia is considerably lower than that of Finland [7] and Sweden $[3,8]$. In these two countries the incidence of Type 1 diabetes tends to decrease after the age of 15 years $[7,8]$ as in some other populations $[2,9,10$, 11]. Our data are similar to two reports from New Zealand $[12,13]$. In one report it was shown that the propensity to diabetes remained high at least until 19 years [12], the other documented a postpubertal second peak in Type 1 diabetes incidence at 16 years of age [13]. The Type 1 diabetes incidence in Estonia in 1988 of 39.9 in the age group 15-19 years is comparable with the peak incidence levels at the age groups 5-9 and 10-14 years in Finland, where the annual average incidence was 39.0 and 45.4 per 100,000 , respectively for $1981-1985$ [3].
Nevertheless it should be pointed out, that the high incidence of Type 1 diabetes in the age group 15-19 years could partly result from the short observation period and from year to year fluctuations in the number of new cases.

The Type 1 diabetes incidence among the adult population in Estonia, differed somewhat from a Danish report, where it was about 10 per 100,000 after the age of 50 years [5]. In Estonia a significant decline in the incidence of Type 1 diabetes after the age of 50 was seen (i. e. 3.4 per 100,000 ).

It has been suggested that populations should be categorized into high, medium or low Type 1 diabetes risk groups based on the incidence data for the age group 0-20 years [1]. Countries with a Type 1 diabetes incidence over 15 per 100,000 per year are considered to be high risk countries [1]. According to these criteria Estonia can be added to the list of high-risk countries as the incidence was 16.7 per 100,000 in 1988 .

The fact that the prevalence of Type 1 diabetes in the age group 15-19 years was not significantly lower than that of the subsequent age group is of special interest. Even though no detailed investigations have been carried out, it seems unlikely that such a trend in Type 1 diabetes prevalence in the age group 20-29 is due to an increased mortality in that group. It has been documented that the incidence of childhood Type 1 diabetes has markedly increased in some countries during the late 1970s and early 1980s [3]. If the same trend holds true for Estonia the detected pattern of Type 1 diabetes prevalence in 1988 could be explained. This question will be addressed in further ongoing studies.

Acknowledgements. This report was prepared during a visit of Dr. T.Podar to the Department of Epidemiology, National Public Health Institute, Helsinki, Finland, under the bilateral scientific exchange programme between the Finnish and Estonian Institutes which is supported by the Ministries of Health of the Soviet Union and Finland. We are indepted to the regional paediatricians, endocrinologists and internists who treat diabetes in Estonia for providing the data for this study from their records. We would like to especially thank Dr. B.Adojaan, the head of the Organizational Department of the Republic Endocrinology Centre, Tartu, Estonia and Mrs. T.Pollus from the same department for the enormous work involved in the data collection. We are especially grateful to Prof. J.Tuomilehto and Assistant Prof. E.Tuomilehto-Wolf from the National Public Health Institute, Helsinki, Finland, for their help in preparing this manuscript. Our special thanks also to Prof. H. Akerblom, Assistant Prof. A. Reunanen and Dr. R.Lounamaa, Helsinki, Finland, for support and useful comments on the manuscript.

\section{References}

1. LaPorte RE, Tajima N, Åkerblom HK, Berlin N, Brosseau J, Christy M, Drash AL, Fishbein H, Green A, Hamman R, Harris M, King H, Laron Z, Neil A (1985) Geographic differences in the risk of insulin-dependent diabetes mellitus. Diabetes Care [Suppl] 8: 101-107

2. Diabetes Epidemiology Research International (1987) Preventing insulin-dependent diabetes mellitus: the environmental challenge. Br Med J 295: 479-481 
3. Rewers M, LaPorte RE, King H, Tuomilehto J (1988) Trends in the prevalence and incidence of diabetes: insulin-dependent diabetes mellitus in childhood. World Health Stat Q 41: 179-189

4. WHO Study Group (1985) Diabetes mellitus. Technical Report Series, Geneva 727, p 77

5. Christau B, Mölbak AG (1984) Further epidemiological evidence of a higher incidence level for the insulin-dependent diabetes mellitus in the older age groups. In: Advance abstracts of papers of the 19th Annual Meeting of the Scandinavian Society for the Study of Diabetes, Trondheim, 14-16 June 1984. Acta Endocrinol [Suppl] 95: 18

6. Silla R (1983) Eesti noorsoo tervisest. Tartu Riiklik Ulikool

7. Reunanen A, Åkerblom HK, Käär ML (1982) Prevalence and ten-year incidence of insulin-dependent diabetes mellitus in children and adolescents in Finland. Acta Paediatr Scand 71: 893-899

8. Östman J, Arnquist H, Blohme G, Lithner F, Littorin B, Nyström L, Sandström A, Schersten B, Wall S, Wibell L (1986) Epidemiology of diabetes mellitus in Sweden. Acta Med Scand 220: $437-445$

9. Green A, Andersen PK (1983) Epidemiological studies of diabetes mellitus in Denmark: 3. Clinical characteristics and incidence of diabetes among males aged 0 to 19 years. Diabetologia $25: 226-230$
10. Vaandrager GJ, Bruining GJ, Veenhof FJ, Drayer NM (1984) Incidence of childhood diabetes in the Netherlands: a decrease from north to south over North-Western Europe? Diabetologia 27: 203-206

11. Bingley BJ, Gale EAM (1989) Incidence of insulin dependent diabetes in England: a study in the Oxford region, 1985-6. Br Med J 298: $558-560$

12. Crossley JR, Upsdell M (1980) The incidence of juvenile diabetes mellitus in New Zealand. Diabetologia 18: 29-34

13. Mason DR, Scott RS, Darlow BA (1987) Epidemiology of insulin-dependent diabetes mellitus in Canterbury, New Zealand. Diab Res Clin Prat 3: 21-29

Received: 4 September 1989

and in revised form: 27 November 1989

Dr. T.Podar

c/o Prof. J. Tuomilehto

National Public Health Institute

Mannerheimintie 166

SF-00300 Helsinki

Finland 